\title{
Organocatalytic synthesis of vinylene carbonates
}

\author{
Killian Onida, ${ }^{[a]}$ Alice J. Haddleton, ${ }^{[b]}$ Sébastien Norsic, ${ }^{[b]}$ Christophe Boisson, ${ }^{[b]}$ Franck D'Agosto ${ }^{[b]}$ and \\ Nicolas Duguet ${ }^{\star[a]}$
}

[a] K. Onida, Dr N. Duguet

Université de Lyon, Université Claude Bernard Lyon 1, CNRS, INSA-Lyon, CPE-Lyon, Institut de Chimie et Biochimie Moléculaires et Supramoléculaires, ICBMS, UMR 5246, team CAtalyse, SYnthèse et ENvironnement (CASYEN).

Bâtiment Lederer, 1 rue Victor Grignard, F-69622 Villeurbanne cedex, France.

E-mail: nicolas.duguet@univ-lyon1.fr

[b] Dr A. J. Haddleton, Dr S. Norsic, Dr C. Boisson, Dr F. D'Agosto

Université de Lyon, Univ. Lyon 1, CPE Lyon, CNRS UMR 5128, Laboratory of Catalysis Polymerization Processes and Materials (CP2M)

Bat 308F, 43 Bd du 11 Novembre 1918, F-69616 Villeurbanne, France.

\begin{abstract}
The organocatalytic synthesis of vinylene carbonates from benzoins and acyloins was studied using diphenyl carbonate as a carbonyl source. A range of $\mathrm{N}$-Heterocyclic Carbene $(\mathrm{NHC})$ precursors were screened and it was found that imidazolium salts were the most active for this transformation. The reaction occurs at $90^{\circ} \mathrm{C}$ under solvent-free conditions. A wide range of vinylene carbonates (symmetrical and unsymmetrical, aromatic or aliphatic), including some derived from natural products, were prepared with 20$99 \%$ isolated yields (24 examples). The reaction was also developed using thermomorphic polyethylene-supported organocatalysts as recoverable and recyclable species. The use of such species facilitates the workup and allows the synthesis of vinylene carbonates on the preparative scale (> $30 \mathrm{~g}$ after 5 runs).
\end{abstract}

Organic carbonates are currently the subject of intense research efforts, notably due to their general innocuity and biodegradability. Consequently, they have found numerous applications in electrolytes for lithium batteries, ${ }^{1}$ renewable solvents ${ }^{2}$ and monomers for the preparation of polycarbonates ${ }^{3}$ and nonisocyanate polyurethanes (NIPUs). ${ }^{4}$ In this vast field, organic cyclic carbonates largely dominate as they can be prepared from epoxides and $\mathrm{CO}_{2}$, using a plethora of catalysts. ${ }^{5}$

In contrast, the chemistry of vinylene carbonates is considerably underdeveloped. Among these species, vinylene carbonate (1,3dioxol-2-one) is the most representative. Similar to ethylene carbonate, vinylene carbonate can be used as an electrolyte additive in lithium batteries (Scheme 1, a). ${ }^{6}$ Moreover, its unsaturated nature facilitates its use in other kind of applications. For example, it can be used for the preparation of poly(vinylenecarbonate) ${ }^{7}$ through radical (co-)polymerization (Scheme 1, b). The resulting polymer can be further hydrolyzed to poly(hydroxymethylene), that has recently found applications in 3D printing. ${ }^{8}$ Vinylene carbonates are also used in the medical field, notably in prodrugs such as olmesartan medoxomil ${ }^{9}$ and azilsartan medoxomil, ${ }^{10}$ where they serve as cleavable group to release the active species (Scheme $1, \mathrm{c}){ }^{11}$

In organic chemistry, vinylene carbonate is mainly used as a dienophile in Diels-Alder reactions ${ }^{12}$ and other cycloadditions, ${ }^{13}$ but also as a coupling partner in arylation reactions. ${ }^{14}$

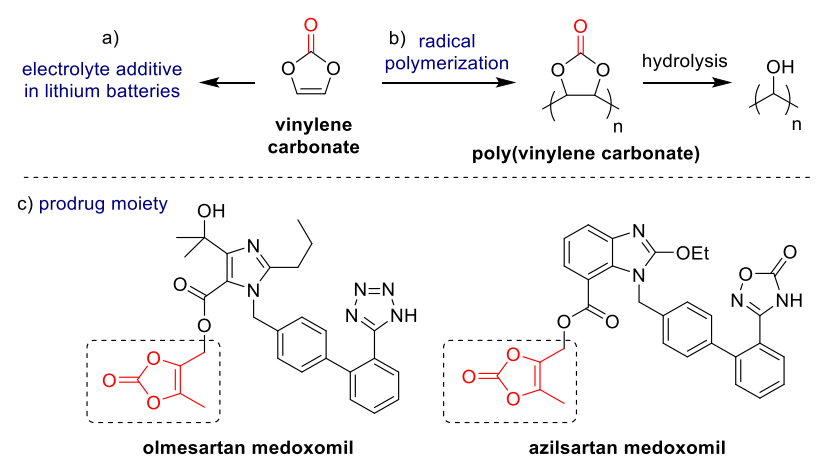

Scheme 1. Main applications of vinylene carbonates.

Recently, vinylene carbonate has been mainly used as an acetylene ${ }^{15}$ or ethynol ${ }^{16}$ surrogate in annulation reactions. ${ }^{17}$ Moreover, it was also demonstrated that it can act as an acetylation reagent in rhodium-catalyzed cyclization. ${ }^{18}$ Despite all of these various applications, the chemistry of vinylene carbonates remains undeveloped, mainly due to their limited availability linked to their problematic synthesis.

The synthesis of vinylene carbonate was first reported from ethylene carbonate using a chlorination / dehydrochlorination sequence (Scheme 2, a). ${ }^{19}$ This route has been developed industrially; however, it involves the use of chlorine gas and generates chlorinated byproducts, thus leading to tedious purification. The silver-catalyzed reaction of propargylic alcohols with $\mathrm{CO}_{2}$ affords exo-vinylene carbonates (also called $\alpha$-vinylene carbonates), ${ }^{20}$ that constitute another family of carbonates as they have different electronic properties, reactivities and applications. In some occasions, i.e. when the substrate is carefully designed, exo-vinylene carbonates can be isomerized to endo-vinylene carbonates (Scheme 2, b). ${ }^{21}$ However, this route is not general as only a limited range of products can be prepared through this method. The reaction of benzoins or acyloins with carbonylating agents affords vinylene carbonates in a straightforward way (Scheme 2, c). Moreover, this route is probably the most general as it allows the preparation of a wide range of products. 
a) Chloration / dehydrochloration of ethylene carbonate

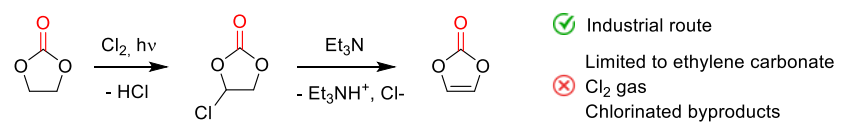

b) Silver-catalyzed cyclization of propargyl alcohols with $\mathrm{CO}_{2}$

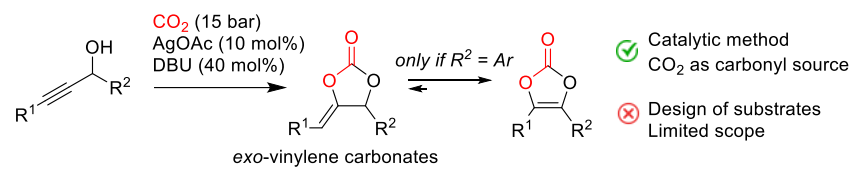

c) Cyclization of benzoins / acyloins with carbonylating agents

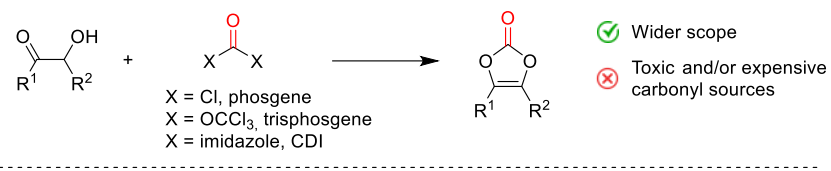

d) First organocatalytic approach using carbonates [this work]

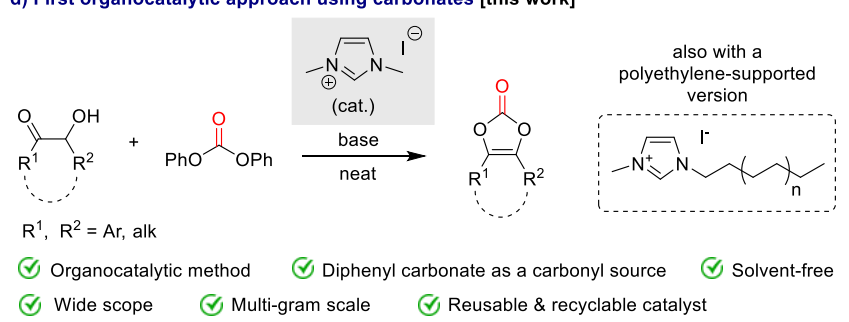

Scheme 2. Main strategies for the preparation of vinylene carbonates.

The use of phosgene as a carbonylating agent usually leads to excellent yields but raises health and safety concerns. ${ }^{13 a, 22}$ Trisphosgene can be used as an alternative. ${ }^{23}$ However, the release of phosgene cannot be avoided. ${ }^{24}$ Alternatively, the preparation of vinylene carbonates can be achieved using carbonyl di-imidazole (CDI). ${ }^{25} \mathrm{CDI}$ is a mild carbonylating agent and hence it has to be used in excess, which is a drawback considering that it is expensive. Moreover, its production involves phosgene, so the problem is displaced considering the overall process. In this context, it would be highly desirable to prepare vinylene carbonates using organic carbonates (e.g., dimethyl or diphenyl carbonate) as carbonyl sources. ${ }^{26}$ Indeed, such species are generally less toxic and safer to use. Moreover, they are produced from ethylene carbonate, so they also derive from $\mathrm{CO}_{2}$. On the downside, they are less reactive, so the use of catalysis is mandatory to activate such species.

To the best of our knowledge, no catalytic method has been reported for the direct preparation of vinylene carbonates from benzoins or acyloins. In this context, we report here the first organocatalytic method for the preparation of vinylene carbonates using diphenyl carbonate as a carbonyl source (Scheme 2, d). Moreover, the method was further developed with thermomorphic polyethylene-supported organocatalysts, additionally providing efficient, recoverable and recyclable catalysts that facilitates both the workup and the upscaling of the process.

The reaction was developed using diphenyl carbonate (DPC) as a carbonyl source considering that it is a reactive carbonate, which is obtained on an industrial scale for the production of polycarbonates. ${ }^{27}$ The reaction of benzoin $\mathbf{1}$ with diphenyl carbonate 2 was first investigated with a range of $\mathrm{NHC}$ precursors (5 mol\%) in the presence of $\mathrm{K}_{2} \mathrm{CO}_{3}(5 \mathrm{~mol} \%)$ at $90^{\circ} \mathrm{C}$ for 2 hours under solvent-free conditions (Table 1 ).
Table 1. Screening of NHC precursors and bases. ${ }^{[a]}$

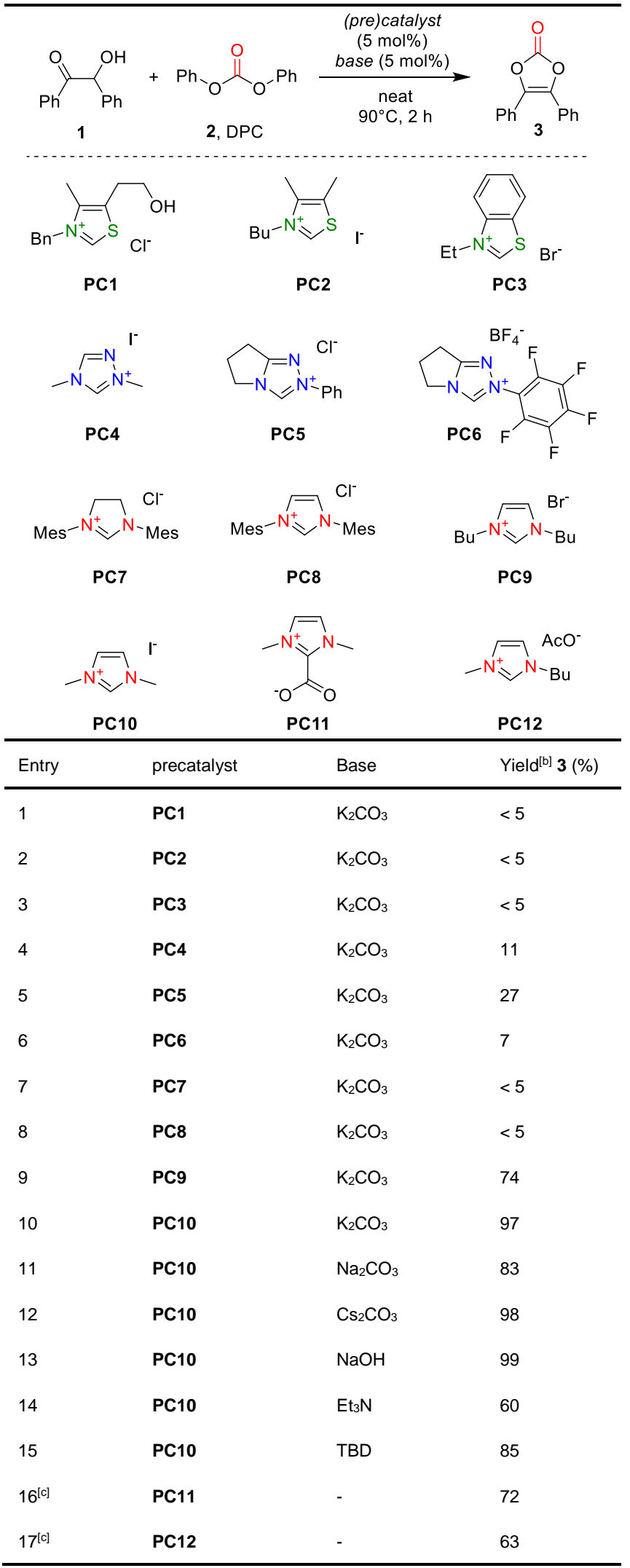

[a] Reaction conditions: benzoin 1 (1 mmol), diphenylcarbonate 2 (1.1 mmol), precatalyst $(5 \mathrm{~mol} \%)$, base $(5 \mathrm{~mol} \%), 90^{\circ} \mathrm{C}, 2 \mathrm{~h}$. [b] Yields were determined by GC/FID with $n$-hexadecane as an internal standard. [c] Reactions were performed without external base. TBD $=1,5,7$-triazabicyclo [4.4.0]dec-5-ene. 
Under these conditions, only traces of vinylene carbonate $\mathbf{3}$ were obtained using thiazolium salts PC1-PC3 (entries 1-3). Triazolium salts PC4 and PC5 led to the formation of the product with very moderate yields, however higher than the one obtained when pentafluorophenyl anologue PC6 was used (entries 4-6). Popular NHC ligands SIMes (PC7) and IMes (PC8) were tested here as organocatalysts but only traces of product were detected, probably due to steric reasons (entries 7-8). On the contrary, dibutylimidazolium bromide PC9 led to the formation of $\mathbf{3}$ with $74 \%$ yield (entry 9). Satisfyingly, the use of less-hindered dimethylimidazolium iodide PC10 led to an excellent $97 \%$ yield (entry 10). Other bases were also tested. The use of $\mathrm{Na}_{2} \mathrm{CO}_{3}$ led to a lower yield while $\mathrm{Cs}_{2} \mathrm{CO}_{3}$ gave a similar result than $\mathrm{K}_{2} \mathrm{CO}_{3}$ (entries 11-12). The results could be explained by a better solubility of these inorganic carbonates in the (neat) reaction mixture. Interestingly, $\mathrm{NaOH}$ also gave a full conversion of benzoin $\mathbf{1}$ to vinylene carbonate $\mathbf{3}$ (entry 13). However, the use of such base should be avoided due to its ability to hydrolyze vinylene carbonates upon heating and/or prolonged reaction time. Organic bases such as $\mathrm{Et}_{3} \mathrm{~N}$ and triazabicyclodecene (TBD) also gave the desired product but with lower yields (entries 14-15). Finally, NHC- $\mathrm{CO}_{2}$ adduct PC11 and imidazolium acetate PC12 were tested without external base thanks to their ability to generate in-situ the free carbene, which is supposed to be the active species in this process. Considering that they gave lower yields (entries 16-17) than the precatalyst/base couple, PC10 was selected as organocatalyst for further optimization. Control experiments were performed using either $\mathrm{PC} 10$ or $\mathrm{K}_{2} \mathrm{CO}_{3}$ but only traces of the desired carbonate $\mathbf{3}$ were obtained, thus indicating the combined crucial role of both species in the catalytic system. Several reaction parameters were next investigated (Table 2).

Table 2. Optimization of precatalyst and base loadings. ${ }^{[a]}$

\begin{tabular}{|c|c|c|c|c|}
\hline$\overbrace{\mathrm{Ph}}^{\mathrm{O}}{ }_{\mathrm{Ph}}^{\mathrm{OH}}$ & $+\mathrm{Ph}_{2}$ & $\mathrm{~K}_{2} \mathrm{C}$ & $\begin{array}{l}\mathrm{N}^{-} \\
10 \\
0 \mathrm{O} \%) \\
(x \mathrm{~mol} \%) \\
\mathrm{at} \\
2 \mathrm{~h}\end{array}$ & ${ }_{{ }_{2}}^{\mathrm{O}}=<_{\mathrm{Ph}}^{\mathrm{O}}$ \\
\hline Entry & $\begin{array}{l}\text { DPC, } 2 \\
\text { (equiv) }\end{array}$ & $\begin{array}{l}\text { Precatalyst } \\
\text { PC10 } \\
\text { loading } \\
\left(\text { mol\%) }{ }^{1}\right.\end{array}$ & $\begin{array}{l}\mathrm{K}_{2} \mathrm{CO}_{3} \\
\text { loading } \\
\text { (mol\%) }\end{array}$ & $\begin{array}{l}\text { Yield }^{[b]} \mathbf{3} \\
(\%)\end{array}$ \\
\hline 1 & 1.1 & 5 & 5 & 96 \\
\hline 2 & 2 & 5 & 5 & 82 \\
\hline 3 & 3 & 5 & 5 & 38 \\
\hline 4 & 1.1 & 1 & 1 & $<5$ \\
\hline 5 & 1.1 & 0.1 & 0.1 & $<5$ \\
\hline 6 & 1.1 & 10 & 10 & 90 \\
\hline 7 & 1.1 & 20 & 20 & 89 \\
\hline 8 & 1.1 & 5 & 10 & 85 \\
\hline 9 & 1.1 & 5 & 20 & 71 \\
\hline 10 & 1.1 & 5 & 50 & 99 \\
\hline
\end{tabular}

[a] Reaction conditions: benzoin 1 (1 mmol), diphenylcarbonate (DPC) 2 (1.1-3 $\mathrm{mmol}$ ), 1,3-dimethylimidazolium iodide $\mathrm{PC} 10, \mathrm{~K}_{2} \mathrm{CO}_{3}, 90^{\circ} \mathrm{C}, 2 \mathrm{~h}$. [b] Yields were determined by GC/FID with $n$-hexadecane as an internal standard.

Increasing the amount of 2 from 1.1 to 3 equivalents led to a drastic drop in yield (entries 1-3). This result has been attributed to the dilution of the reaction medium under solvent-free conditions. Decreasing both the precatalyst and base loadings to 1 and $0.1 \mathrm{~mol} \%$ led to very poor yields (entries 4-5), while increasing them to 10 and $20 \mathrm{~mol} \%$ only slightly affected the yield of 3 , which reaches 90 and $89 \%$, respectively (entries 6-7). Subsequently, the concentration of $\mathrm{K}_{2} \mathrm{CO}_{3}$ was studied with a precatalyst loading set at $5 \mathrm{~mol} \%$. Adding 2 to 4 times more base slightly decreased the yield to $71 \%$ (entries $8-9$ ). Interestingly, increasing the base to $50 \mathrm{~mol} \%$ gave full conversion of benzoin 1 and an excellent $99 \%$ yield for the desired vinylene carbonate 3 (entry 10)

Other organic carbonates were tested as a carbonyl source (Table 3). Dimethyl and diethyl carbonates $\mathbf{4}$ and $\mathbf{5}$ were first used but only traces of 3 were obtained, despite the use of $4 \AA$ molecular sieves (entries 1-2). In these two cases, benzil was observed as the only product. The formation of benzil from benzoin has been already reported by Okumura under similar conditions. ${ }^{28}$ Ethylene and propylene carbonates 6 and 7 were also considered as carbonyl sources as they directly arise from the cycloaddition of ethylene and propylene oxides with $\mathrm{CO}_{2}$. However, no reaction occurred with such carbonates and the starting material was recovered unaltered (entries 3-4).

Table 3. Screening of carbonates as carbonyl sources. ${ }^{[\mathrm{a}]}$

[a] Reaction conditions: benzoin 1 (1 mmol), carbonate 2, 4-8 (1.1 mmol), 1,3dimethylimidazolium iodide PC10 (5 mol\%), $\mathrm{K}_{2} \mathrm{CO}_{3}(5 \mathrm{~mol} \%), 90^{\circ} \mathrm{C}, 2 \mathrm{~h}$. [b] Yields were determined by GC/FID with $n$-hexadecane as an internal standard. [c] 3 equivalents of carbonate and $4 \AA \mathrm{MS}(100 \mathrm{mg} / 20 \mathrm{mg}$ of alcohol) were used. 
Finally, catechol carbonate $\mathbf{8}$, prepared following a reported method, ${ }^{29}$ proved to be a good candidate as it gave vinylene carbonate 3 with $71 \%$ yield (entry 5), but it is not competing with diphenyl carbonate (entry 6). The success of the reaction when diphenyl carbonate 2, or catechol carbonate $\mathbf{8}$ to a lesser extent, was used probably lies in the leaving group ability of the phenolate ion by comparison with other alcoholates. The substrate scope was then investigated using the optimized conditions (Scheme 3).
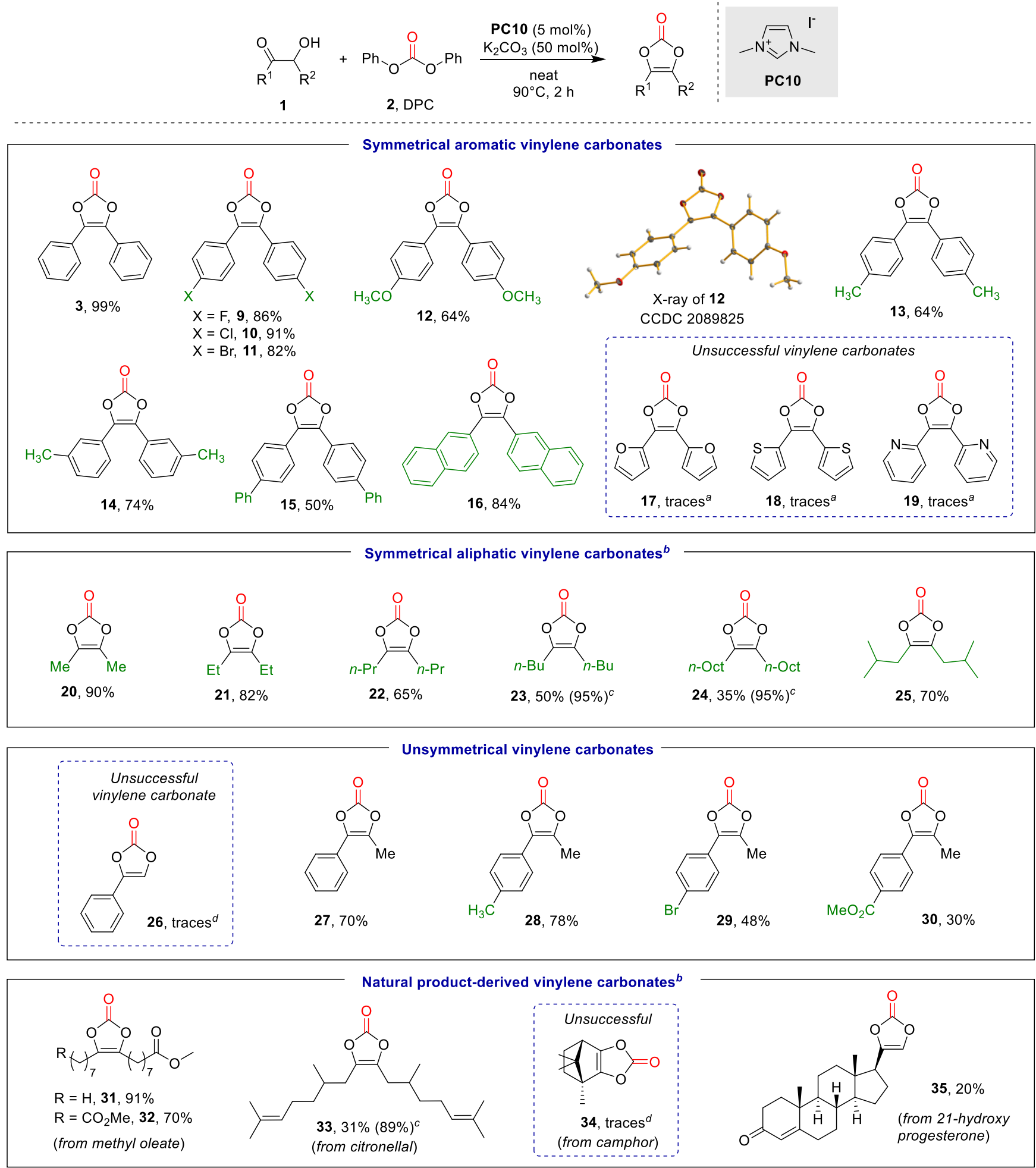

Scheme 3. Scope of vinylene carbonates. Yields of isolated products are given. ${ }^{a}$ The corresponding diketones were obtained as major products. ${ }^{b} 3$ equivalents of diphenyl carbonate were used. ${ }^{c} \mathrm{GC}$ yields in brackets. ${ }^{d}$ The mixed carbonate intermediate was obtained as major product. 
Symmetrical benzoins were first considered and benzoin gave the corresponding vinylene carbonate $\mathbf{3}$ with an excellent $99 \%$ yield. Good yields were also obtained using para-substituted benzoins bearing halogen such as fluorine $(86 \%, 9)$, chlorine $(91 \%, 10)$ or bromine $(82 \%, 11)$. The use of anisoin gave 12 , with $64 \%$ yield, whose structure was confirmed by X-ray. The reaction was also successful with para- and meta-methyl groups, giving 13 and 14 with 64 and $74 \%$ yield, respectively. However, the corresponding vinylene carbonate bearing ortho-methyl groups could not be produced due to the difficult preparation method of the starting material. Phenyl- and 2-naphthyl substituted benzoins gave carbonates $15-16$ with 50 and $84 \%$ yield. In contrast, vinylene carbonates 17-19 bearing heteroaromatic groups (2-furanyl, 2thiophenyl, 2-pyridinyl) could not be prepared under the optimized conditions. In these cases, the corresponding 1,2-diketones were formed, probably through NHC-catalyzed decarbonylation of instable vinylene carbonate intermediates. ${ }^{30}$ Symmetrical acyloins were then tested under the standard conditions. However, despite a full conversion, only traces of the desired carbonates were detected due to the formation of a mixed carbonate intermediate (see ESI). The formation of such product is probably favored by the high concentration of the (neat) reaction medium and the low steric hindrance around the hydroxyl function of the acyloin. The problem was solved by increasing the amount of diphenyl carbonate to three equivalents. These new conditions were successfully applied to several symmetrical linear acyloins leading to the corresponding vinylene carbonates 20-24 with $35-90 \%$ isolated yields. It is worth noting that compound $\mathbf{2 0}$ is the key starting material for the preparation of the medoxomil group in prodrugs. Vinylene carbonate $\mathbf{2 5}$ bearing isobutyl groups was also produced in good yield (70\%). Unsymmetrical aryl alkyl acyloins were next considered. Unfortunately, carbonate $\mathbf{2 6}$ could not be obtained from 2-hydroxy-1-phenylethan-1-one, due to the formation of a mixed carbonate, that was found to prohibit cyclization. On the contrary, with an extra methyl group, the cyclization occurs smoothly and vinylene carbonates 27-30 were prepared with decent yields (30-78\%). Finally, natural-product derived acyloins were also considered. Vinylene carbonates $\mathbf{3 1}$ and 32, derived from methyl oleate and its self-metathesis derivative, were obtained with high yields. The use of citronellal led to $\mathbf{3 3}$ with a moderate isolated yield, while the camphor derivative only gave traces of $\mathbf{3 4}$ due to the formation of a mixed carbonate intermediate. Finally, vinylene carbonate $\mathbf{3 5}$ derived from 21-hydroxyprogesterone was obtained with $20 \%$ yield.

Overall, we have developed an organocatalytic method for the synthesis of vinylene carbonates with good yields on a wide scope. Recovery and reuse of the catalyst might be the next step for an even improved method. Indeed, in this context, we have recently developed thermomorphic polyethylene-supported organocatalysts for the preparation of saturated cyclic carbonates by $\mathrm{CO}_{2}$ insertion into epoxides, ${ }^{31}$ including vegetable oil derivatives. ${ }^{32}$ The thermomorphic behavior of the polyethylene support allows the catalyst to exhibit similar reactivity to a homogeneous systems while being fully recyclable. Therefore, we envisioned that such innovative supported catalysts would be perfectly suitable for the synthesis of vinylene carbonates.

Hence, several supported imidazolium salts were prepared with various polyethylene molar masses, thus giving organocatalysts PC13-PC17 with number-average molar masses $\left(M_{n}\right)$ ranging from 740 to $1800 \mathrm{~g} \mathrm{~mol}^{-1}$ (see ESI for details). These supported organocatalysts were tested at $90^{\circ} \mathrm{C}$ for the model reaction using benzoin 1 and diphenylcarbonate 2 as substrates (Table 4). A quantitative yield of vinylene carbonate 3 was obtained using short chain catalysts PC13 and PC14, with a $M_{n}$ of 740 and 850 g. $\mathrm{mol}^{-1}$, respectively (entries 1-2). However, the yield of 3 progressively decreased from 54 to $23 \%$ with catalysts PC15PC17 which have higher molar masses $\left(M_{\mathrm{n}}\right.$ of 1000,1500 and $1800 \mathrm{~g} \mathrm{~mol}^{-1}$, entries 3-5). This phenomenon could be explained by the fact that catalysts with high molar masses are not completely melted in the reaction mixture at $90^{\circ} \mathrm{C}$. These results also suggest a direct correlation between molar masses / melting temperatures (determined by DSC in Table 4) of the catalysts and their catalytic activity. To confirm our hypothesis, the reaction was performed at $120^{\circ} \mathrm{C}$. As expected, a quantitative yield of 3 was obtained for all supported catalysts at such temperature (entries $1-5$, results in brackets). These results clearly highlight the tunability of the thermomorphic polyethylene-supported organocatalysts to address reactions at various temperature.

Table 4. Synthesis of vinylene carbonate using polyethylene-supported organocatalysts. ${ }^{\text {[a] }}$

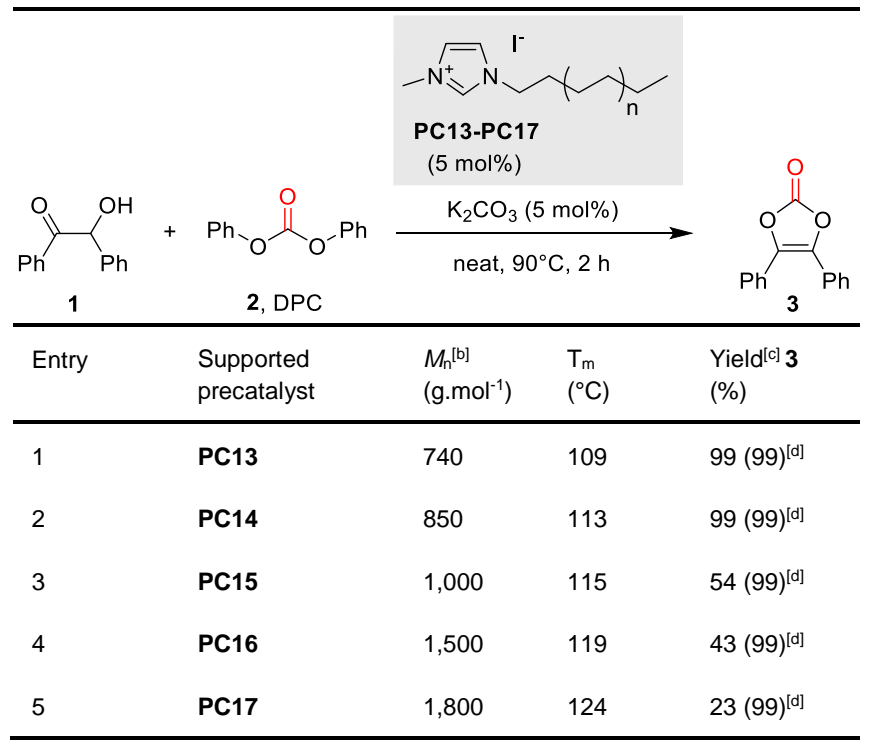

[a] Reaction conditions: benzoin 1 (1 mmol), diphenylcarbonate $2(1.1 \mathrm{mmol})$, thermomorphic polyethylene-supported organocatalysts PC13-PC17 (5 mol\%), $\mathrm{K}_{2} \mathrm{CO}_{3}(5 \mathrm{~mol} \%), 90^{\circ} \mathrm{C}, 2 \mathrm{~h}$. [b] $M_{\mathrm{n}}$ were determined by ${ }^{1} \mathrm{H}$ NMR. [c] Yields were determined by GC/FID with $n$-hexadecane as an internal standard. [d] Reactions were performed at $120^{\circ} \mathrm{C}$.

To further highlight the interest of such supported organocatalysts, recycling studies were performed on the model reaction using precatalyst PC14 (5 mol\%) and $\mathrm{K}_{2} \mathrm{CO}_{3}(5 \mathrm{~mol} \%)$ at $90^{\circ} \mathrm{C}$ (Figure 2). The reaction was initially carried out using $30 \mathrm{mmol}$ of benzoin. After reaction, the catalyst precipitates upon cooling and was filtered over sintered glass (EtOAc was added to facilitate the filtration). The desired vinylene carbonate $\mathbf{3}$ was obtained from the filtrate with $98 \%$ yield $(7.0 \mathrm{~g})$. The catalyst was recovered with $99 \%$ yield and reused as such for further reactions. The catalyst proves to be recyclable over five consecutive runs without significant loss of activity (94-99\% yield, Figure 2, blue bars). About $33 \mathrm{~g}$ of vinylene carbonate 3 were obtained by combining all products recovered from each run, thus highlighting the synthetic utility of our method on the preparative scale (Figure 2, orange curve). 


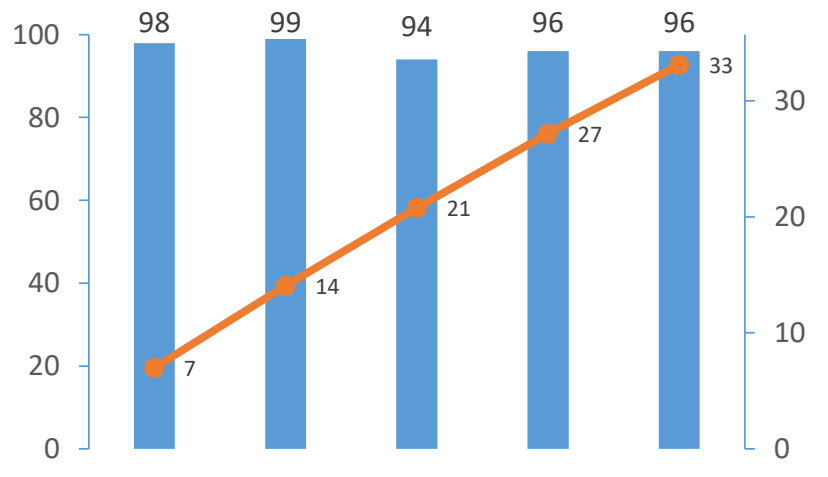

Figure 2. Recycling studies of thermomorphic polyethylene-supported organocatalysts. Blue bars represent yield (\%) of vinylene carbonate 3 and orange curve represents the cumulative mass of 3 produced over the runs. The reactions were performed with benzoin (30 mmol for runs 1-3, $28 \mathrm{mmol}$ for run 4 and $26 \mathrm{mmol}$ for run 5,1 equiv), diphenylcarbonate (1.1 equiv), precatalyst PC14 ( $\left.\mathrm{M}=860 \mathrm{~g} \mathrm{~mol}^{-1}, 5 \mathrm{~mol} \%\right), \mathrm{K}_{2} \mathrm{CO}_{3}(5 \mathrm{~mol} \%)$ and were stirred at $90^{\circ} \mathrm{C}$ for 2 hours. The yields were determined by GC/FID with $n$-hexadecane as an internal standard.

${ }^{1} \mathrm{H}$ NMR analysis of the recovered catalyst after five runs did not show any sign of degradation, indicating that the catalyst is quite robust under the tested conditions (see ESI). However, the presence of aromatic signals in the ${ }^{1} \mathrm{H}$ NMR spectrum suggested that the original iodine ion has been partially exchanged with a phenolate ion. This has probably occurred through protonation of the free carbene with phenol. ${ }^{33}$ To confirm this hypothesis, catalyst PC18 was prepared from PC14 by ion metathesis using potassium phenolate (Scheme $4, a$ ). The ${ }^{1} \mathrm{H}$ NMR spectrum of both PC18 and recovered PC14 were found to be identical, thus confirming our hypothesis. Catalyst PC18 was then tested in the model reaction in absence of $\mathrm{K}_{2} \mathrm{CO}_{3}$ external base (Scheme $4, \mathrm{~b}$ ). Vinylene carbonates $\mathbf{3}$ was obtained in quantitative yield, indicating the ability of the phenolate ion to act as an internal base to generate the active species.

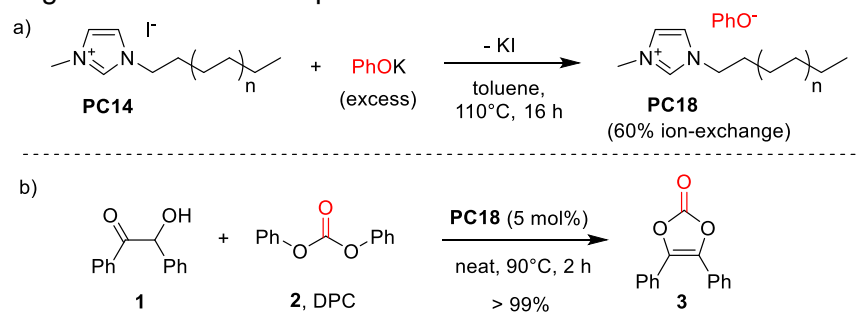

Scheme 4. Preparation of catalyst PC18 by anion metathesis (top) and its use in the synthesis of vinylene carbonate without external base (bottom).

In conclusion, we have developed the first organocatalytic method to prepare vinylene carbonates from benzoins and acyloins using diphenyl carbonate as a carbonyl source. A wide range of symmetrical and unsymmetrical vinylene carbonates was produced (24 examples, including renewable substrates) with 20$99 \%$ isolated yield, thus considerably increasing the scope of synthesized products over the existing methods. Moreover, we have also developed this method using thermomorphic polyethylene-supported organocatalysts, which proved to be as active as their unsupported analogues. Their recoverability, reusability and recyclability were demonstrated over five runs.
Finally, the method was also implemented on the multi-gram scale, thus demonstrating its synthetic utility.

\section{Acknowledgements}

The authors thank the French National Agency for Research for financial support through a Ph.D. grant to K. Onida and a postdoctoral fellowship to A. J. Haddleton (ANR-19-CE07-0006ThermoPESO). L. G. Borrego Sanchez de la Cuesta and L. Ibrahimli are thanked for their help to prepare some of the starting materials. The authors would like to thank the Centre Commun de RMN de Lyon (A. Baudoin, E. Chefdeville, C. Gilbert) for NMR analyses. E. Jeanneau (Centre De Diffractométrie Henri Longchambon, Université Claude Bernard Lyon1) is also acknowledged for X-Ray analyses.

Keywords: Vinylene carbonates • Benzoin • Diphenyl carbonate - Organocatalysis • Thermomorphic polyethylene

[1] G. Girishkumar, B. McCloskey, A. C. Luntz, S. Swanson, W. Wilcke, J. Phys. Chem. Lett. 2010, 1, 2193-2203.

[2] B. schäffner, F. Schäffner, S. P. Verevkin, A. Börner, Chem. Rev. 2010 110, 4554-4581.

[3] a) D. J. Darensbourg, Chem. Rev. 2007, 107, 2388-2410; b) B. Grignard, S. Gennen, C. Jerome, A. W. Kleij, C. Detrembleur, Chem. Soc. Rev. 2019, 48, 4466-4514.

[4] a) M. S. Kathalewar, P. B. Joshi, A. S. Sabnis, V. C. Malshe, RSC Adv 2013, 3, 4110-4129; b) G. Rokicki, P. G. Parzuchowski, M. Mazurek Polym. Adv. Technol. 2015, 26, 707-761; c) A. Cornille, R. Auvergne, O. Figovsky, B. Boutevin, S. Caillol, Eur. Polym. J. 2017, 87, 535-552; d) P. Furtwengler, L. Averous, Polym. Chem. 2018, 9, 4258-4287; e) C. Carre, Y. Ecochard, S. Caillol, L. Averous, ChemSusChem, 2019, 12, 34103430 .

[5] T. Sakakura, K. Kohno, Chem. Commun. 2009, 1312-1330; b) M. North, R. Pasquale, C. Young, Green Chem. 2010, 12, 1514-1539; c) J. W. Comerford, I. D. V. Ingram, M. North, X. Wu, Green Chem. 2015, 17, 1966-1987; d) C. Martín, G. Fiorani, A. W. Kleij, ACS Catal. 2015, 5, 1353-1370; e) H. Büttner, L. Longwitz, J. Steinbauer, C. Wulf, T. Werner, Top. Curr. Chem. 2017, 375, 1-56; f) R. R. Shaikh, S. Pornpraprom, V. D’Elia, ACS Catal. 2018, 8, 419-450; g) A. J. Kamphuis, F. P. Picchioni, P. P. Pescarmona, Green Chem. 2019, 21, 406-448; h) V. Aomchad, À. Cristòfol, F. Della Monica, B. Limburg, V. D’Elia, A. W. Kleij, Green Chem. 2021, 23, 1077-1113.

[6] a) D. Aurbach, K. Gamolsky, B. Markovsky, Y. Gofer, M. Schmidt, U. Heider, Electrochim. Acta 2002, 47, 1423-1439; b) S. Park, S. Y. Jeong T. K. Lee, M. W. Park, H. Y. Lim, J. Sung, J. Cho, S. K. Kwak, S. Y. Hong, N.-S. Choi, Nat. Commun. 2021, 12, 838.

[7] a) L. Ding, Y. Li, Y. Li, Y. Liang, J. Huang, Eur. Polym. J. 2001, 37, $2453-$ 2459; b) Kumru, N. Bicak, RSC Adv. 2015, 5, 30936-30942.

[8] a) B. Stolz, F. Mönkemeyer, M. Mader, S. Schmidt, L. Volk, T. Steinberg, B. Bruchmann, R. Mülhaupt, Macromol. Chem. Phys. 2020, 221 2000132; b) B. Stolz, M. Mader, L. Volk, T. Steinberg, R. Mülhaupt Macromol. Mater. Eng. 2021, 306, 2000541.

[9] K. S. Babu, M. S. Reddy, A. R. Tagore, G. S. Reddy, S. Sebastian, M. S Varma, G. Venkateswarlu, A. Bhattacharya, P. P. Reddy, R. V. J. S. C. Anand, Synth. Commun. 2008, 39, 291-298.

[10] S. Rádl, J. Černý, J. Stach, Z. Gablíková, Org. Process Res. Dev. 2013, 17, 77-86.

[11] J. Alexander, D. S. Bindra, J. D. Glass, M. A. Holahan, M. L. Renyer, G. S. Rork, G. R. Sitko, M. T. Stranieri, R. F. Stupienski, H. Veerapanane, J. J. Cook, J. Med. Chem. 1996, 39, 480-486.

[12] a) M. E. Jung, R. B. Blum, B. J. Gnede, M. R. Gider, Heterocycles 1989 , 28, 93-97; b) S. V. D'Andrea, J. P. Freeman, J. Szmuszkovicz, J. Org Chem. 1990, 55, 4356-4358; c) C. Taffin, G. Kreutler, D. Bourgeois, E. 
Clot, C. Périgaud, New J. Chem. 2010, 34, 517-525; d) K. Afarinkia, A. Bahar, J. Neuss, Synlett 2003, 15, 2341-2344; e) J. Daub, V. Trautz, Tetrahedron Lett. 1970, 37, 3265-3268; f) M. Z. Haq, J. Org. Chem. 1972 , 37, 3015-3019

[13] a) H.-M. Fischler, H.-G. Heine, W. Hartmann, Tetrahedron Lett. 1972, 17, 1701-1704.

[14] a) K. H. Kim, B. R. Park, J. W. Lim, J. N. Kim, Tetrahedron Lett. 2011, 52, 3463-3466; b) Z. Wang, F. Xue, T. Hayashi, Angew. Chem. Int. Ed. 2019, 58, 11054-11057.

[15] a) K. Ghosh, Y. Nishii, M. Miura, ACS Catal. 2019, 9, 11455-11460; b) G. Mihara, K. Ghosh, Y. Nishii, M. Miura, Org. Lett. 2020, 22, 5706-5711 c) K. Ghosh, Y. Nishii, M. Miura, Org. Lett. 2020, 22, 3547-3550; d) X. Li, T. Huang, Y. Song, Y. Qi, L. Li, Y. Li, Q. Xiao, Y. Zhang, Org. Lett. 2020 22, 5925-5930; e) B. Shen, S. Liu, L. Zhu, K. Zhong, F. Liu, H. Chen, R Bai, Y. Lan, Organometallics 2020, 39, 2813-2819; f) L. Wang, K.-C. Jiang, N. Zhang, Z.-H. Zhang, Asian J. Org. Chem. 2021, DOI:10.1002/ajoc.202100247.

[16] a) H. Hara, M. Hirano, K. Tanaka, Org. Lett. 2009, 11, 1337-1340; b) Z. H. Wang, H. Wang, H. Wang, L. Li, M.-D. Zhou, Org. Lett. 2021, 23, 995999.

[17] Y. Nishii, M. Miura, ACS Catal. 2020, 10, 9747-9757.

[18] a) C. Wang, X. Fan, F. Chen, P.-C. Qian, J. Cheng, Chem. Commun. 2021, 57, 3929-3932; b) J. Nan, Q. Ma, J. Yin, C. Liang, L. Tian, Y. Ma Org. Chem. Front. 2021, 8, 1764-1769.

[19] a) M. S. Newman, R. W. Addor, J. Am. Chem. Soc. 1953, 75, 1263 1264; b) M. S. Newman, R. W. Addor, J. Am. Chem. Soc. 1955, 77, 3789-3793.

[20] a) B. Wang, S. Sun, J. Cheng, Synlett 2018, 1814-1822; b) K. Sekine, T. Yamada, Chem. Soc. Rev. 2016, 45, 4524-4532; c) G. Shi, R. Zhai, H. Li, C. Wang, Green Chem. 2021, 23, 592-596; d) A. Cervantes-Reyes, K. Farshadfar, M. Rudolph, F. Rominger, T. Schaub, A. Ariafard, A. S. Hashmi, Green Chem. 2021, 23, 889-897.

[21] R. Ugajin, S. Kikuchi, T. Yamada, Synlett 2014, 25, 1178-1180.

[22] M. Torres, J. Ribo, A. Clement, O. P. Strausz, Can. J. Chem. 1983, 61, 996-998.

[23] a) D. P. Sahu, Indian J. Chem. 2002, 41B, 1722-1723.

[24] L. Cotarca, T. Geller, J. Répási, Org. Process Res. Dev. 2017, 21, 1439 1446.

[25] M. M. Krayushkin, S. N. Ivanov, A. Yu. Martynkin, B. V. Lichitsky, A. A. Dudinov, L. G. Vorontsova, Z. A. Starikova, B. M. Uzhinov, Russ. Chem. Bull., Int. Ed. 2002, 51, 1731-1736.

[26] Some methods involving carbonylating agents such as alkyl chloroformates, carbonates, and others, have been claimed in patents but their feasibility were not demonstrated elsewhere. a) J. Zhao, J. Wen, L. Wang, X. Lv, J. Fu, R. Liu, Y. Chen, L. Wang, J. Zhao, Chinese patent CN107892681, 2018; b) Y. Bao, Chinese patent, CN103483307, 2014 c) F. Xiao, N. Zhao, J. Yang, X. Wang, Z. Liu, Chinese patent CN104059047, 2014; d) Y. Bao, Chinese patent, CN103483308, 2014 b) H. Niu, Chinese patent, CN106905288, 2017, e) B. Wan, G. Lin, Y Wu, J. Liu, H. Yu, J. Hu, C. Wang, S. Lu, Chinese patent, CN110981848 2020; f) X. Wang, X. Guan, X. Wang, Chinese patent, CN111393403, 2020.

[27] S. Fukuoka, M. Kawamura, K. Komiya, M. Tojo, H. Hachiya, K. Hasegawa, M. Aminaka, H. Okamoto, I. Fukawa, S. Konno, Green Chem. 2003, 5, 497-507.

[28] Y. Okumura, J. Org. Chem. 1963, 28, 1075-1079.

[29] T. Tabanelli, E. Monti, F. Cavani, M. Selva, Green Chem. 2017, 19, 1519-1528.

[30] For carbene-catalyzed carbonylation of a diketone to carbonate, see: J. L. Peltier, E. Tomás-Mendivil, D. R. Tolentino, M. M. Hansmann, R Jazzar, G. Bertrand, J. Am. Chem. Soc. 2020, 142, 18336-18340.

[31] K. Grollier, N. D. Vu, K. Onida, A. Akhdar, S. Norsic, F. D’Agosto, C. Boisson, N. Duguet, Adv. Synth. Catal. 2020, 362, 1696-1705.

[32] A. Akhdar, K. Onida, N. D. Vu, K. Grollier, S. Norsic, C. Boisson, F. D'Agosto, N. Duguet, Adv. Sustainable Syst 2021, 5, 2000218.

[33] J. A. Cowan, J. A. C. Clyburne, M. G. Davidson, R. L. W. Harris, J. A. K. Howard, P. Küpper, M. A. Leech, S. P. Richards, Angew. Chem. Int. Ed. 2002, 41, 1432-1434. 


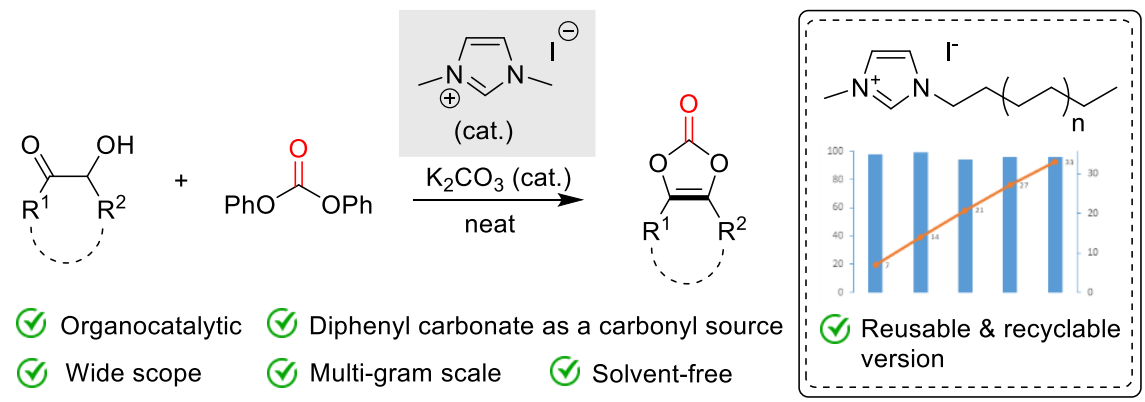

Vinylene carbonates were prepared from benzoins / acyloins using diphenyl carbonate as a carbonyl source. The reaction is catalyzed by imidazolium salts under solvent-free conditions. The reaction was also developed using thermomorphic polyethylene-supported organocatalysts as recoverable and recyclable species, allowing the synthesis of vinylene carbonates on the multigram scale. 